\title{
Violência contra a mulher por parceiro íntimo: contextos online e offline
}

\author{
Pâmela Fardin Pedruzzi \\ Agnaldo Garcia
}

\section{RESUMO}

A pesquisa investigou características da violência contra a mulher por parceiro íntimo de maneira online e offline, seus impactos no relacionamento em questão e no enfrentamento desta violência. Participaram doze mulheres com alta escolaridade que reportaram terem experienciado violência em um relacionamento com um parceiro íntimo e que fizessem uso de pelo menos uma rede social virtual no momento do relacionamento relatado. 0 procedimento de coleta de dados foi por meio da técnica bola de neve, utilizando-se da entrevista episódica. A análise temática foi usada para categorizar os dados. Nos resultados, dois temas foram identificados: (a) violência offline no relacionamento; e (b) violência online no relacionamento. 0 primeiro tema indicou que os tipos de violência experienciados foram físicos, psicológicos e sexuais. Características como "isolamento social", "medo de reagir", "culpabilização da vítima" e a "violência como um ciclo" foram percebidas de maneira offline. O segundo tema apontou para o uso da internet no relacionamento como ferramenta de controle pelo parceiro, como meio de registro de provas da violência e como facilitador de acesso à informação. Sugere-se que novas pesquisas abordem diferentes variáveis sociodemográficas, a fim de investigar percepções variadas acerca da violência online e offline em um relacionamento romântico.

Palavras-chave: Violência contra a mulher; Violência doméstica; Internet; Redes sociais.

\section{ABSTRACT \\ Intimate partner violence against women: online and offline contexts}

The research investigated characteristics of violence against women by an intimate partner in an online and offline way, its impacts on the relationship in question, and coping with the violence. Twelve women with access to higher education who reported having experienced violence in a relationship with an intimate partner and utilized at least one virtual social network during the reported relationship participated. Data collection procedure was made by the snowball technique, using episodic interviews. Thematic analysis was used to categorize the data. In the results, two themes were identified: (a) offline violence in the relationship; and (b) online violence in the relationship. The first theme indicated that the types of violence experienced were physical, psychological, and sexual. Characteristics such as "social isolation," "fear of reacting," "blaming the victim," and "violence as a cycle" were perceived offline. The second theme pointed to the use of the internet in relationships as a control tool by the partner, as a way to record evidence of violence, and as an access to information facilitator. It is suggested that new research in the field addresses different sociodemographic variables to investigate different perceptions about online and offline violence in a romantic relationship.

Keywords:Violence Against Women; Domestic Violence; Internet; Social Networks.

A violência por parceiro íntimo é considerada pela Organização Mundial de Saúde (OMS) como um fenômeno de saúde pública. Pode incluir abusos psicológicos, físicos e sexuais e é considerado um dos tipos mais comuns de violência contra a mulher (OMS, 2012, 2017). Mes-

\section{Sobre os autores}

\section{P. F. P.}

http://orcid.org/0000-00030869-8602

Universidade Federal do Espírito Santo - ES

pamfardin@hotmail.com

A. G. http://orcid.org/0000-0002-

1937-7399

Universidade Federal do Espírito Santo - ES

agnaldo.garcia@uol.com.br

\section{Direitos Autorais}

Este é um artigo de acesso aberto e pode ser reproduzido livremente, distribuído, transmitido ou modificado, por qualquer pessoa desde que usado sem fins comerciais. 0 trabalho é disponibilizado sob a licença Creative Commons CC-BY-NC.

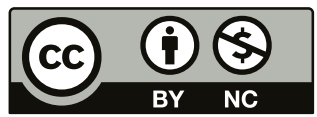




\section{M." INTERACÃO EM PSICOLOGIA}

mo que a violência por um parceiro íntimo não tenha somente mulheres como vítima, entre os diferentes tipos de violência, o parceiro ou ex-parceiro íntimo (namorado, noivo, marido, entre outros) figura como um dos principais autores das agressões contra o gênero (Waiselfisz, 2015). Dados indicam que uma a cada três mulheres poderão experienciar algum tipo violência por um parceiro ou não-parceiro durante a vida (OMS, 2013, $2019,2020)$. Dessa maneira, em casos de violência doméstica entre casais, comumente a mulher acaba se tornando a vítima, em especial ao se considerar relações de poder e gênero que existem em um relacionamento, como terrorismo íntimo, controle, isolamento, culpa, entre outros (Albuquerque Netto et al., 2017; Cortez, 2006).

No Brasil, com base em dados divulgados pelo Atlas da Violência 2020 (Cerqueira et al., 2020), no período de 2013 a 2018, é destacado um aumento de homicídios femininos dentro de suas próprias residências (8,3\%) em comparação a ambientes externos (redução de 11,8\%). Considerando o ano de 2018, em casos de mortes de mulheres, $30,4 \%$ foram feminicídios; o que segundo o documento, ressalta a ligação desse tipo de crime com a violência doméstica. Também é relevante o aumento de $25 \%$ em mortes de mulheres dentro das residências por armas de fogo entre 2013 a 2018 (Cerqueira et al., 2020). A OMS (2012) define feminicídio como o homicídio de uma mulher devido a seu gênero. Dessa forma, pensando no registro de casos em ambientes residenciais, acredita-se que o principal autor da violência pode ser alguém próximo à mulher, como o parceiro íntimo, por exemplo (Cerqueira, 2014).

As definições de deveres e direitos masculinos e femininos em um relacionamento podem ser influenciadas por papéis e concepções biológicas de gênero, particularmente no contexto latino-americano (Blay, 2014). Dessa maneira, a identificação da violência em um relacionamento por muitas vezes é de difícil reconhecimento, principalmente quando as agressões não acontecem fisicamente (Parker, 2015). Tal obstáculo na identificação é discutido inclusive no atendimento às vítimas, principalmente por conta da reprodução de preconcepções de tais papéis de gênero (Pedrosa \& Spink, 2011; Scarpati, 2013). Sendo assim, diversas perspectivas são investigadas a fim de auxiliar o entendimento da violência contra a mulher por parceiro íntimo (Guimarães \& Diniz, 2017). Alguns exemplos envolvem análises de denúncias (Cortez, 2012); investigação de consequências psicológicas para as vítimas (Beydoun et al., 2017; Nascimento et al., 2018); impacto no contexto familiar e suporte da rede social (Colossi et al., 2015; Dutra et al., 2013); e de possibilidades de intervenção (Cardoso \& Costa, 2019; Carline et al., 2018; Cunha \& Nascimento, 2015), por exemplo.

Considerando os relacionamentos românticos, pesquisas abordam o uso de tecnologias como facilitadoras de práticas sociais e de comunicação entre pessoas (Haack \& Flacke, 2013; Recuero, 2012). Rocha (2015) indica que as tecnologias ao serem mais acessíveis e presentes no cotidiano, consequentemente também são usadas como veículos que colaboram com a exposição de violências objetivas, subjetivas e simbólicas. A reprodução de violências online pode ir desde o impedimento do acesso à internet, até ao uso dos serviços como mediadores, por exemplo (Estébanez \& Vasquez, 2013). Segundo a Comissão de Banda Larga para o Desenvolvimento Digital da ONU (The Broadband Comission for Digital Development), pesquisas e discussões sobre a violência contra a mulher que acontece de maneira online são necessárias, pois esse também é um espaço que pode ser usado como facilitador, se tornando um problema social (UN Women, 2015).

O cyberbullying é comumente investigado nesse contexto, especialmente entre o público infanto-juvenil. Ele é caracterizado por ser um tipo de agressão repetitiva e intencional que acontece de maneira online, evidenciando uma relação de poder entre o agressor e a vítima e gerando consequências nas relações presenciais (Patchin \& Hinduja, 2006). A violência online contra a mulher por parceiro íntimo segue uma semeIhante premissa ao considerar que "violências" que acontecem online (utilizam a internet e serviços de tecnologias de informação como espaços) e offline (presenciais, físicas e/ ou que não aconteçam de maneira virtual) estão relacionadas (UN Women, 2015). De maneira parecida com o cyberbullying, a violência online realizada pelo parceiro íntimo também pode refletir no dia a dia, acarretando em consequências para a muIher vítima (Marganski, 2013). Martinéz-Pecino e Duran (2016) ao investigarem cyberbullying entre estudantes universitários destacaram que o uso do celular e da internet para a prática de algum tipo de violência com um parceiro íntimo foi reportado (48,4\% e $37,5 \%$, respectivamente). Os autores também apontaram que existiu correlação entre concepções sexistas entre os homens da amostra com as práticas de cyberbullying com uma companheira pelo celular $(r=0,24, p<.05)$ e pela internet $(r=0,26, p<.05)$.

Marganski e Melander (2015) ao investigarem quantitativamente a violência online e offline/presencial por parceiros íntimos em 884 estudantes universitários americanos, reportaram que a maioria (cerca de $73 \%$ ) dos participantes disseram terem vivido algum tipo de violência online no relacionamento. As autoras também destacam que atos de violência praticados em espaços online e offline estão interligados. Dentre os participantes que relataram terem sido vítimas de violência online, a maioria reportou também terem vivenciado algum tipo de agressão psicológica, física e sexual; $94,8 \%$, 96\% e 92,6\%, respectivamente (Marganski \& Melander, 2015).

Nesse contexto, algumas práticas violentas online recebem nomes específicos. Alguns exemplos são o harassment/ cyberstalking (perseguição); o sexting (mensagens de natureza sexual trocadas de maneira virtual) que quando não consensuais, podem culminar no revenge porn (pornô de vingança) 


\section{INTERACÃO EM LF. PSICOLOGIA}

(Belknap et al., 2012; Flach \& Deslandes, 2017; Messinger et al., 2018). A perseguição realizada de maneira online é abordada como uma forma de controle do parceiro íntimo sobre a mulher, onde este detém poder sobre o uso da internet e das redes sociais da companheira, impedindo ou manipulando o contato com sua rede de apoio (Borrajo et al., 2015; Flach \& Deslandes, 2017).

O sexting já foi abordado como uma prática positiva dentro de um relacionamento romântico, porém suas consequências negativas têm chamado a atenção com o passar dos anos (Drouin et al., 2017). Como exemplo, revenge porn (pornô de vingança) é considerado um produto do sexting e tem como característica o compartilhamento de mídias íntimas e de conteúdo sexual (vídeos, fotos, mensagens, etc.) sem o consentimento da pessoa envolvida (Citron \& Franks, 2014), sendo que tal distribuição geralmente ocorre após o término de um relacionamento, configurando-se em uma vingança (Bates, 2016).

Considerando estes como fenômenos recentes, a tipificação jurídica pode ser de difícil definição (Burris, 2014). Porém, além das legislações voltadas à proteção da mulher, já existem políticas públicas brasileiras que envolvem aspectos de crimes cometidos através das tecnologias e da internet. Assim, é possível citar a "Lei Carolina Dieckmann" (2012), que diz sobre delitos informáticos e teve sua origem a partir de uma invasão aos aparelhos da atriz Carolina Dieckmann, tendo conversas e fotos íntimas vazadas na internet sem o seu consentimento. Outra lei que circunda esse contexto é a chamada "Lei Lola" (2018) que dá poder à Polícia Federal para a investigação de discursos misóginos e de ódio contra mulheres online. A Lei foi promulgada a partir de episódios caracterizados como violência de gênero, experienciados pela ativista Lola Aronovich (Agência Senado, 2018).

Assim, parte-se do pressuposto que atos de violência realizados por um parceiro íntimo contra uma mulher que acontecem de maneira online (através de serviços que utilizam internet e tecnologias de informação), possam estar ligados aos que acontecem presencialmente, sem a mediação de serviços virtuais (chamados de "offline") em um relacionamento. Dessa forma, sabendo que esta interação é um fenômeno em crescimento, a presente pesquisa investigou características da violência contra a mulher por parceiro íntimo de maneira online e offline, seus impactos no relacionamento em questão e no enfrentamento desta violência sob a perspectiva de mulheres com alta escolaridade.

\section{MÉTODO}

\section{PARTICIPANTES}

Foram entrevistadas 12 mulheres que relataram ter experienciado algum tipo de violência por parceiro íntimo durante um relacionamento romântico e fazerem uso de pelo menos uma rede social no momento da coleta. A idade variou de 22 a 39 anos $(M=27,42 ; D P=4,42)$. $A$ tabela 1 descreve as entrevistadas com base no questionário sociodemográfico realizado, juntamente com nomes fictícios adotados para preservar o anonimato das mulheres. 


\section{H NTERAC̄óOEM ET PSICOLOGIA}

Tabela 1: Caracterização das participantes

\begin{tabular}{|c|c|c|c|c|c|}
\hline Participante & Idade & Profissão & Escolaridade & Estado civil & $\begin{array}{l}\text { Tempo do relacio- } \\
\text { namento relatado }\end{array}$ \\
\hline Paula & 27 & Estudante & $\begin{array}{l}\text { Superior incom- } \\
\text { pleto }\end{array}$ & $\begin{array}{l}\text { Solteira (namo- } \\
\text { rando) }\end{array}$ & 6 meses \\
\hline Bianca & 26 & $\begin{array}{l}\text { Engenheira } \\
\text { civil }\end{array}$ & $\begin{array}{l}\text { Superior com- } \\
\text { pleto }\end{array}$ & $\begin{array}{l}\text { Solteira (namo- } \\
\text { rando) }\end{array}$ & 2 anos e 2 meses \\
\hline Eduarda & 30 & $\begin{array}{l}\text { Servidora pú- } \\
\text { blica }\end{array}$ & $\begin{array}{l}\text { Superior com- } \\
\text { pleto }\end{array}$ & Solteira & 4 anos \\
\hline Amanda & 27 & Psicóloga & $\begin{array}{l}\text { Pós-graduação } \\
\text { completa }\end{array}$ & $\begin{array}{l}\text { Solteira } \\
\text { (namorando) }\end{array}$ & 1 ano e 6 meses \\
\hline Isabela & 22 & Estudante & $\begin{array}{l}\text { Superior incom- } \\
\text { pleto }\end{array}$ & $\begin{array}{l}\text { Solteira } \\
\text { (namorando) }\end{array}$ & 2 meses \\
\hline Alice & 26 & $\begin{array}{l}\text { Engenheira } \\
\text { civil }\end{array}$ & $\begin{array}{l}\text { Superior com- } \\
\text { pleto }\end{array}$ & $\begin{array}{l}\text { Solteira } \\
\text { (namorando) }\end{array}$ & 2 anos e 5 meses \\
\hline Maria & 39 & Psicóloga & $\begin{array}{l}\text { Pós-graduação } \\
\text { completa }\end{array}$ & Solteira & 40 dias \\
\hline Bruna & 26 & Advogada & $\begin{array}{l}\text { Pós-graduação } \\
\text { completa }\end{array}$ & Solteira & 4 anos \\
\hline Juliana & 26 & Redatora & $\begin{array}{l}\text { Superior com- } \\
\text { pleto }\end{array}$ & Solteira & 2 anos \\
\hline Aurora & 22 & $\begin{array}{l}\text { Agente de ae- } \\
\text { roporto }\end{array}$ & $\begin{array}{l}\text { Superior incom- } \\
\text { pleto }\end{array}$ & Solteira & 3 meses \\
\hline Sara & 28 & Psicóloga & $\begin{array}{l}\text { Pós-graduação } \\
\text { completa }\end{array}$ & $\begin{array}{l}\text { Solteira } \\
\text { (namorando) }\end{array}$ & 3 anos \\
\hline Mirela & 30 & Psicóloga & $\begin{array}{l}\text { Pós-graduação } \\
\text { completa }\end{array}$ & $\begin{array}{l}\text { Solteira } \\
\text { (namorando) }\end{array}$ & $\begin{array}{l}2 \text { anos e } 9 \text { meses } / 2 \\
\text { anos e } 6 \text { meses* }\end{array}$ \\
\hline
\end{tabular}

*Nota: A participante Mirela relatou dois relacionamentos românticos que considerou violentos, portanto, dois tempos de duração são sinalizados.

Em relação ao nível de escolaridade, todas tiveram acesso ao ensino superior. Três participantes cursando graduação e dentre as mulheres com nível superior completo, cinco reportaram terem pós-graduação completa. Quanto ao trabalho, duas participantes disseram não estar trabalhando, dedicando-se somente aos estudos. Além disso, quatro mulheres eram psicólogas.
Os relacionamentos mencionados aconteceram de maneira presencial, todos heterossexuais. Nenhuma das mulheres esteve casada com o parceiro em questão, porém algumas relataram ter morado junto com o parceiro por no mínimo um mês. 0 tempo de duração do relacionamento correspondeu a dois anos, em média. Dentre as participantes, todas estavam solteiras no momento da coleta de dados, porém sete comuni- 


\section{M." INTERACÃO EM PSICOLOGIA}

caram estarem em outro relacionamento, namorando. Na seção de resultados, a identificação das falas das participantes será feita através do nome fictício e idade.

Instrumento e procedimentos de coleta de dados. 0 acesso às participantes deu-se por meio da técnica bola de neve, utilizando-se de cadeias de referência (Vinuto, 2014). A escolha de tal técnica foi feita pela possibilidade de utilizar um informante-chave para se aproximar do grupo a ser investigado. Inicialmente, o recrutamento de participantes foi compartilhado na rede social Instagram, em um perfil de divulgação científica sobre o tema "violência contra a mulher", com a descrição dos critérios de inclusão. Oito mulheres retornaram o contato com o interesse de participar da pesquisa. Após as entrevistas, a partir de suas indicações, foi possível receber referências de outras potenciais participantes de seus círculos de amizade que poderiam contribuir com o estudo. Para estipular o número de participantes, a técnica de saturação foi utilizada. Dessa forma, ao atingir um grau na qual as informações provenientes da coleta são essenciais para os temas da análise, a quantidade de entrevistas se torna adequada (Ando et al., 2014).

A entrevista episódica for utilizada para coleta de dados. A escolha desse procedimento visou se aproximar das participantes, por meio das narrativas de suas experiências, direcionando assim a pesquisa para episódios específicos de acordo com os objetivos da pesquisa (Flick, 1998/2008). O instrumento utilizado para a realização das entrevistas foi um roteiro composto por questões sociodemográficas, e levantamento sobre a história do relacionamento violento; o uso das redes sociais tanto pela vítima, quanto pelo agressor; bem como as formas de enfrentamento de tal tipo de violência e a mediação das tecnologias de informação nesse processo. Assim, buscou-se que tais questões favorecessem como incentivos narrativos para facilitar a aproximação dos dados à realidade das entrevistadas (Flick, 1998/2008).

A coleta de dados foi realizada presencialmente, de maneira individual, na universidade, conforme agendamento prévio com cada participante e teve duração média de 50 minutos.

Análise de dados. 0 método escolhido para análise dos dados foi a análise temática. Braun e Clarke (2006) descrevem que esta técnica permite investigar padrões de significado com maior flexibilidade e detalhes, visando liberdade teórica e utilizando-se de um caráter indutivo. Assim, temas e códigos são criados a fim de investigar os dados coletados com base nos objetivos da pesquisa, por meio do desenvolvimento de tabelas e mapas temáticos.

Questões éticas. A pesquisa foi aprovada no Comitê de Ética em Pesquisa da Universidade Federal do Espírito Santo, sob o CAAE 06931118.0.0000.5542. A colaboração das mulheres esteve condicionada à apresentação e assinatura do Termo de Consentimento Livre e Esclarecido (TCLE), na qual foi possível elucidar questões acerca da participação, registro das informações e riscos e/ou benefícios do estudo.

\section{RESULTADOS E DISCUSSÃO}

Por meio da análise temática, os resultados foram divididos em dois temas: a "violência offline no relacionamento", que abordou características e percepções acerca da violência experienciada presencialmente, no relacionamento com o parceiro íntimo pelas participantes sem a utilização de serviços virtuais; e "violência online no relacionamento", que descreveu a utilização da internet e das tecnologias de informação nos episódios violentos relatados, tanto pela vítima, quanto pelo agressor.

Violência offline no relacionamento. s tipos de violência identificados e vivenciados, segundo as participantes, foram a violência física, psicológica e sexual. A violência física foi um dos tipos mais relatados e compreenderam tapas, arranhões, socos, empurrões e marcas na pele. As entrevistadas se preocuparam em ressaltar nas suas narrativas que a violência em um relacionamento com parceiro íntimo vai muito além dos aspectos físicos, também abrange consequências psicológicas e emocionais. Dessa forma, angústias, medo e dúvidas quanto as próprias ações foram algumas consequências consideradas negativas frente a episódios de agressividade verbal, humilhações, ameaças, traições, perseguições e coerções provocados pelo parceiro íntimo.

Tem do dia que ele... ele tinha o costume de me beliscar. Do nada. Ele falava que era porque me achava fofinha. Aí eu falava que isso me machucava, porque isso me deixava cheia de marca de roxo. E aí de tanto que ele me beliscou, eu não podia mais usar camisa sem manga ou com manga curta. Ou eu não podia mais usar short. Porque a minha perna era toda marcada de roxo de tanto levar beliscão (Aurora, 22 anos).

Era sempre uma agressão verbal, psicológica. Sempre me rebaixando. Tipo: "Você, ah, você é horrível, seu cabelo é horrível, você é muito baixinha...", sempre dessa forma pra me fazer mal, me sentir péssima (Eduarda, 30 anos).

Schraiber et al (2007) apontam que o conceito "violência psicológica" tem variações frente a perspectivas como cultura e gênero, podendo ocorrer de muitas formas, dificultando assim sua definição e identificação. Nesse contexto, o fato de as mulheres entrevistadas utilizarem o termo em seus relatos é digno de nota. Foi possível perceber que mesmo que as definições de violência psicológica sejam variadas, todas mostraram ter consciência da presença deste tipo em seu relacionamento, colaborando assim para a ampliação da definição de violência pelas participantes. 


\section{H. INTERACÃO EM LTPSICOLOGIA}

Quando a gente pensa em violência, a primeira coisa que me vem à cabeça é a violência física. Tanto que é muito difícil da gente parar e pensar que uma manipulação pode ser violência. Se eu fosse te dar um conceito, violência é tudo aquilo que a pessoa se sente agredida. Então essa forma de agressão é física, essa forma de agressão é mental, essa forma de agressão é de invasão de espaço. Então tudo que invade o espaço, eu imagino que seja que seja violência (Amanda, 27 anos).

Nesse sentido, a percepção da violência experienciada pode ser considerada um aspecto importante nesse contexto. As descrições das participantes apontaram que durante o relacionamento, diversos fatores contribuíram para que a identificação da violência fosse dificultada, somente se tornando mais evidente após o término da relação. 0 isolamento social, o medo de reagir, culpabilização da vítima e a violência como um ciclo são exemplos que serão descritos a seguir.

0 isolamento social foi considerado pelas entrevistadas como sendo também um tipo de violência. Na literatura, esse aspecto é citado de maneira a contrastar com o apoio social, pois faz com que a mulher vítima diminua o contato com sua rede de suporte, favorecendo um contexto de dependência do parceiro íntimo (Albuquerque Netto et al., 2017; Cunha \& Nascimento, 2015; Dutra et al., 2013). Este isolamento foi relatado de maneira a destacar um cerceamento do contato com os amigos e com a família facilitado por parte do companheiro, o que colaborava com a ocorrência de manipulações acerca da realidade, dificultando sua reação frente aos episódios violentos. A expressão "deixar em uma bolha" é um exemplo de fala utilizada para descrever esse aspecto.

Porém, para o meu lado pessoal, do meu crescimento pessoal, ele sempre tentou me rebaixar. Ele me olhava com olhos que geralmente a sociedade me via. Eu era uma moça bonita, modéstia parte, nova, com um corpo bonitinho... [...] então assim, se ele não fizesse isso comigo, eu ia ter noção das coisas. 0 meu dia a dia com ele era ruim, isso é a verdade [...]. Ele queria me deixar numa bolha, pra eu não ver o que tinha no resto do mundo. Então eu acabei me afastando (Eduarda, 30 anos).

Um detalhe mencionado pelas participantes com relação a esse contexto é a culpabilização da vítima. Esse aspecto diz respeito a responsabilidade da mulher em "consertar" o relacionamento ou zelar pelo seu bom desenvolvimento. Nesse sentido, muitas desculpas eram pedidas pelas entrevistadas por atos que eram perpetrados pelo parceiro, acreditando que tais erros eram de sua autoria. 0 conceito de culpabilização da vítima atribui equivocadamente a culpa à mulher e não ao agressor, sendo descrito como visões de que a violência experienciada pode ter sido causada por comportamentos julgados inadequados da própria vítima (Cardoso \& Costa, 2019; Schoenmaker et al., 2016).
[...] Depois ele veio, me pediu desculpa, falou que não ia fazer nunca mais, mas ainda assim a culpa era minha, porque eu deixava ele assim. Sempre me lembrava que ele nunca foi assim, ele nunca foi uma pessoa violenta, ele nunca foi uma pessoa ciumenta, nunca foi nada, eu deixei ele assim. Eu que fiz com que ele se tornasse um monstro. Usou exatamente essas palavras (Sara, 28 anos).

Nessa discussão, é possível referenciar a presença da violência sexual mencionada pelas participantes. Segundo elas, tal tipo de violência se deu por meio da coerção facilitada pelo contexto do relacionamento violento, como o envio de nudes e relações sexuais contra a vontade da mulher, por exemplo. Assim, um relato muito comum foi a dúvida quanto ao consentimento. As mulheres somente perceberam que foram vítimas de violência sexual após término do relacionamento, acreditando que tais ações seriam normais e naturais dentro do relacionamento, sendo que o contexto "manipulativo" dificultava a negativa.

A violência sexual, que era uma das violências que ele fazia comigo, de coação para ter o ato sexual, não é uma violência sexual que ele pega a força e estupra. É um estupro por coação, é obrigar a outra pessoa a fazer sexo, se não ele iria me torturar psicologicamente, o sexo que ele queria. Isso tudo é violência [...]. Às vezes quando ele tava distante, ele também pedia foto. Ele me obrigava. Mandava um (nuds) pra ele: "quero mais", "quero assim", "quero assado". Eu que era responsável (Sara, 28 anos).

A OMS (2017) destaca que em uma relação sexual é considerada violenta caso não haja o consentimento de uma das partes. Nesse sentido, é importante evidenciar a culpabilização da vítima em casos de violência sexual. Partindo dos relatos apresentados, é possível identificar que a responsabilidade para o consentimento acaba tendo que vir da mulher, sendo isso inclusive ressaltado nas falas das participantes.

Carline et al. (2018) discutem que em concepções masculinas de gênero, normalmente a mulher é considerada como a responsável pela negativa, caso qualquer ato seja contra a sua vontade. Ou seja, a mulher é colocada em uma posição de "gatekeeper", detentora do consentimento. Segundo os autores, esse ponto de vista é preocupante pois faz com que em casos de violência sexual, a responsabilidade seja frequentemente atribuída à mulher por não ter negado o ato sexual. Porém, por meio das narrativas apresentadas pelas participantes, identificou-se que o contexto coercitivo favorecido pelo parceiro dificultou a percepção da violência no momento do ato sexual e, consequentemente, o consentimento, gerando dúvidas e culpa acerca do acontecido.

Além do termo "violência psicológica", outra definição mencionada pelas participantes foi o de violência como um "ciclo". Tal ciclo diz respeito à manutenção da violência que se perpetuava devido a comportamentos, tanto da vítima, quan- 


\section{M." INTERACÃO EM PSICOLOGIA}

to do parceiro. Além disso, as entrevistadas disseram sobre a percepção de que após o término do relacionamento, o ciclo da violência se repetiu com outras mulheres na qual o ex-companheiro também se relacionou.

E aí brigava e se arrependia. Falava que eu tava doida. Aí chorava e falava: "nossa, me perdoa, não sei o que acontece comigo que eu não consigo deixar de ficar com outras pessoas". Só que ele fez a mesma coisa com pessoas que namoraram ele antes [...]. Eu era a namorada dele agora e ele repetia comigo. Chegou um momento que a gente não tinha um rótulo, mas ele falava pras pessoas que eu era louca, era a mesma situação. Era um ciclo (Amanda, 27 anos).

Violência como um ciclo se assemelha a definição de WaIker (1979), na qual aponta fases que se retroalimentam: fase de tensão, fase violenta e fase da "lua-de-mel". A cada ciclo que se repete, maior o escalonamento, intensidade e frequência, o que também dificulta a percepção do contexto violento e facilita uma acomodação frente a rotina (Guimarães \& Diniz, 2017; Medeiros \& Tavares, 2017). Dessa forma, tal visão amplificada da violência como um ciclo só foi possível, segundo as entrevistadas, após o término do relacionamento, pois esse contexto criava obstáculos para possíveis reações frente a violência.

Internet, violência e relacionamento. Segundo o relato das entrevistadas, a internet é utilizada para entretenimento, para trabalhar, fazer contato com pessoas e para o acesso de informações. As principais redes sociais e ferramentas utilizadas foram o Instagram, Whastapp, Facebook, Youtube, Spotify (para músicas e podcasts), Twitter e Snapchat. O Orkut e MSN foram mencionados como redes que foram usadas durante o relacionamento, mas que hoje são extintas.

0 Instagram foi a rede mais utilizada pelas participantes, principalmente através de seu aplicativo para smartphone. 0 Instagram foi referenciado como fonte de entretenimento, passatempo e informações. A facilidade de acesso a conteúdos selecionados (através da opção "seguir"), o uso incluído na rotina online diária e a popularidade entre seus círculos são algumas das vantagens apontadas quanto ao uso do Instagram pelas entrevistadas. Hoje, o Instagram é considerado atualmente como uma das maiores redes sociais, com em média 1 bilhão de usuários mundialmente (Instagram, 2020).

Através da internet, a violência por parceiro íntimo aconteceu de diversas formas. Usar o ambiente online como ferramenta de controle foi uma característica mencionada por elas. Assim, pegar o celular sem permissão, descobrir sua localização e vigiar as redes sociais da vítima - tanto as atividades que eram feitas online, quanto as postagens realizadas sobre o cotidiano de uma maneira geral - foram algumas das formas de obter informações e controle sobre elas.
[...] é uma forma de controle que ele tem sobre mim. E como eu optei por não ter... eu não afasto ele totalmente. Assim, afasto, mas não quero uma briga [...]. Depois que a gente terminou, teve um dia que ele me mandou mensagem. Foi algo: "Ah tá, agora você vai fazer o curso (que eu comecei depois que terminei com ele) que você faz as terças das seis às sete". Tipo, ele sabia de um curso que eu comecei a fazer depois dele, e sabia de todos os horários que eu fazia e eu fiquei com medo depois da mensagem (Bruna, 26 anos).

Além disso, o isolamento social, mencionado de maneira offline, também ocorreu de maneira online. As entrevistadas relataram que o parceiro por muitas vezes controlava as redes sociais da parceira a fim de limitar o que ela poderia seguir ou deveria deixar de seguir. Messinger et al. (2018) apontam que em uma população de adultos, o monitoramento - também chamado como stalking ou cyberstalking na língua inglesa foi considerado preocupante quando aliado a algum tipo de violência física. Ou seja, segundo os autores, esse monitoramento/controle pode ser difícil de identificar e comumente considerado como pouco sério.

Ele fuçava, né. Os meus amigos lá, a minha rede... e daí ele botava defeito em todos os homens que ele via. Ele pegava e falava: "ah, quem é esse?". Aí eu respondia: "ah, é tal pessoa". "Ah, você é ridícula, não sei o quê... exclui! Faz isso e faz aquilo". Eu nem lembro qual era o termo na época, mas eu lembro que ele ficava fuçando toda hora e mandando eu tirar certos homens, assim, que ele não conhecia, ou que sei lá, de repente ele não gostava, cismava com alguns e pedia pra retirar da rede (Eduarda, 30 anos).

Marganski e Melander (2015) destacam que a investigação de experiências individuais do uso das "novas tecnologias" como ferramentas de violência e de controle são importantes nesse contexto. Assim, uma forma de violência considerada pelas participantes foi a realização de postagens sem o seu consentimento. Tais postagens nas redes sociais, feitas pelo parceiro, ou a pedido dele, tinham como objetivo mostrar publicamente o relacionamento. Um exemplo é a opção fornecida pelo Facebook de marcar no próprio perfil a frase "em um relacionamento sério", que foi acatado pela participante por conta de pedidos insistentes do parceiro íntimo.

Ele me obrigou a colocar "relacionamento sério". Eu não queria. Eu nunca gostei. No meu ex-namorado eu também não coloquei, hoje eu namoro e também não coloco. Eu não gosto de ficar dando detalhes. Ele colocou sem eu querer. "Ah, você não quer no seu, mas eu quero colocar no meu, eu vou colocar". Aí eu: "tá bom... vou colocar". Porque eu sabia que se não colocasse geraria um problema. Eu cedi aí mais uma vez (Bianca, 26a).

Ele falava: "pra te perdoar, eu quero que você faça uma postagem pra mim no Facebook". Meu Facebook antigamente 


\section{H*' INTERACÃO EM PSICOLOGIA}

era recheado de postagens hiper, mega românticas para ele, porque ele queria sempre alguma coisa nova. Não podia ser só um "eu te amo" no Facebook. Tinha que ser com fotos e coisas hiper mega românticas. Então era recheado disso [...] Ele me obrigou a fazer isso, e quando eu olhava eu lembrava e chorava (Sara, 28 anos).

Manifestações de violência online de maneira pública já foram reportadas em publicações científicas (Bates, 2016; Nova et al., 2019). Porém, as entrevistadas destacaram que as publicações mostravam conteúdos positivos, contradizendo a realidade e mostrando erroneamente para o círculo de contatos online que o relacionamento era bom, quando verdade, seu contexto era violento. Ter que assentir com tais postagens, saber da possibilidade do compartilhamento em seu perfil e a exibição pública de seu relacionamento foi fonte de sofrimento e prejuízos sociais, segundo as participantes.

O problema é o público. Porque todo mundo vê, porque tá ali. Tá ali, no Facebook do cara. 0 circo que ele tá armando com uma, agora tá fazendo com outra. E é muito fácil, né. Do cara arrumar uma próxima vítima, porque ele limpa o Facebook dele. E exclui tudo que ele tinha de você. E começa de novo (Maria, 39 anos).

Por outro lado, as participantes também apontaram que a internet teve um papel essencial no enfrentamento da violência. A possibilidade de trocar experiências, realizar contato com sua rede de apoio e ter um local para desabafar foram alguns fatores destacados. Segundo as participantes, esses aspectos foram importantes justamente pela facilidade do acesso à informação que a internet e as redes socais podem propiciar.

[...] na época que eu tava vivendo isso, na internet eu via coisas. Mas quando me deu um insight do que tava acontecendo e aí começa a ver em todo lugar? Então assim, eu comecei a perceber em todo lugar, sobre como um relacionamento deve ser [...]. Então, assim, mulher não tem que virar mãe de ninguém, não tem que cuidar de ninguém. Não tem que mostrar o certo e o errado. Então a internet, as redes sociais, elas me ajudaram a fortalecer isso muito (Amanda, 27 anos).

O uso da internet como suporte informacional já foi mencionado como relevante na literatura (Belknap et al., 2012; Baker \& Careño, 2016). As participantes relataram um "movimento de onda", onde conteúdos relacionados à violência contra a mulher, relacionamento abusivo, assédio, feminismo, empoderamento, entre outros, atualmente vêm até elas por meio de compartilhamento nas redes sociais, de maneira aleatória. Segundo elas, tais informações são repassadas com o intuito de conscientizar outras mulheres sobre o tema. Pereira (2018) discute que este "movimento" comumente é repassado por meio de hashtags (com o uso do símbolo "\#"), comparti-
Ihamento de reportagens jornalísticas sobre o tema, troca de comentários e posts sobre os assuntos. Assim, com base no ponto de vista das entrevistadas, é possível apreender que esta mobilização online está sendo percebida pelas mulheres vítimas de violência e colaborando para ações de enfrentamento através do acesso à informação e a definições de violência por parceiro íntimo.

Outro aspecto apontado como vantagem na utilização da internet e das redes sociais na comunicação com o parceiro é quanto ao registro de provas da violência entre o casal. A utilização de backup foi sinalizada como muito importante nesse contexto. Com uma das entrevistadas, mensagens de texto (SMS) com conteúdo ameaçador foram utilizadas como evidências em um pedido de medida protetiva com base na lei Maria da Penha (2006). Dessa maneira, o registro de tais mensagens proporcionou um sentimento de segurança e uma fonte de comprovação da violência para elas próprias e também para pessoas da rede de apoio, caso seja necessário revisitá-las.

Eu não deletei as conversas que eu tive com ele até hoje. Tá tudo aqui. Eu tenho uma raiva muito grande. Eu tenho backup porque eu não perdi meu Whatsapp. Então eu tenho a conversa, ela tá ali até hoje. Não sei, seja pra conversar com alguém, se alguém quiser ler as coisas que aconteciam, ele tentava me manipular, tá tudo ali (Bianca, 26 anos).

Era Facebook e mensagem de texto. Tanto que as provas... eu botei na Maria da Penha, tanto que até ontem não chamou. Mas eu entrei como ameaça e violência doméstica [...]. Na mensagem tava escrito que ele queria me ver, nem que fosse pela última vez (Maria, 39 anos).

\section{CONSIDERAÇÕES FINAIS}

O estudo abordou características online e offline da(s) violência(s) experienciada(s) por mulheres com alta escolaridade em um relacionamento com um parceiro íntimo. Também foram investigados os impactos da violência no relacionamento vivido e nas formas de enfrentamento. 0 objetivo da pesquisa foi alcançado, na medida em que conseguiu acessar aspectos da violência que aconteceram em ambos espaços: presencialmente no relacionamento (offline) e por meio da utilização de recursos online e de tecnologias da informação (online). Assim, algumas considerações se fazem importantes. 0 contexto do relacionamento foi um fator considerado elementar para analisar os episódios de violência por parceiro íntimo, tanto online, como offline. Vergonha, humilhação, medo de reagir, isolamento social, dependência, são alguns exemplos que permearam os relacionamentos e dificultaram o enfrentamento da situação. 


\section{4.' INTERACÃO EM PSICOLOGIA}

Quanto à internet e as redes sociais, acredita-se que estas são ligadas ao cotidiano e ocupam uma dupla função: positiva e negativa nos relacionamentos. Ressalta-se assim que mesmo que as tecnologias colaboraram para o chamado "ciclo" de violência, como a exposição pública e o uso como ferramenta de controle; também proporcionaram acesso à informação de maneira mais fácil, como ao contribuir para o enfrentamento, aproximar-se do feminismo e na construção de uma definição individual de violência em um relacionamento. Dessa forma, pode-se identificar uma característica indissociável do uso das tecnologias no dia a dia e também durante um relacionamento romântico.

A necessidade de ampliação do grupo de participantes quanto a escolaridade, é uma variável relevante. Nesse sentido, sugere-se em futuras pesquisas que a amostra seja diversificada quanto às variáveis sociodemográficas, com grupos comparativos quanto a percepção da violência. 0 acesso democratizado à internet, o uso das redes sociais para abordar tais temas e perspectivas de parceiros agressores são também salutares.

Considerando a violência por parceiro íntimo como um problema de saúde pública (OMS, 2017), este artigo aborda o fenômeno do papel da internet e das tecnologias de informação nesse contexto.

\section{FINANCIAMENTO}

A pesquisa relatada no manuscrito foi financiada parcialmente pela bolsa de mestrado da primeira autora (CAPES).

\section{DECLARAÇÃO DA CONTRIBUIÇÃO DOS AUTORES:}

Certificamos que todos os autores participaram suficientemente do trabalho para tornar pública sua responsabilidade pelo conteúdo. A contribuição de cada autor pode ser atribuída como se segue:

P.F.P. contribuiu com a investigação, redação do manuscrito original e tabulação dos dados. A. G. contribuiu com a revisão e edição do manuscrito, juntamente da supervisão. P. F. P. e A. G. contribuíram com a administração do projeto, análise formal dos dados, conceitualização e metodologia do presente trabalho.

\section{DECLARAÇÃO DE CONFLITOS DE INTERESSE}

Os autores declaram que não há conflitos de interesse no manuscrito submetido.

\section{REFERÊNCIAS}

Agência Senado (2018, 19 de julho). Senado aprova novas leis para diminuir violência contra mulheres. https://www12.senado.leg.br/noticias/materias/2018/07/19/senado-aprova-novas-leis-para-diminuir-violencia-contra-mulheres

Albuquerque Netto, L., Moura, M. A. V., Queiroz, A. B. A., Leite, F. M. C., \& Fernandes, G. (2017). Isolamento de mulheres em situação de violência pelo parceiro íntimo: uma condição em redes sociais. Escola Anna Nery, 21(1), 1-8. https://doi. org/10.5935/1414-8145.20170007

Ando, H., Cousins, R., \& Young, C. (2014). Achieving saturation in thematic analysis: Development and refinement of a codebook. Comprehensive Psychology, 3(1), 1-7. https://doi. org/10.2466/03.CP.3.4

Baker, C. K., \& Carreño, P. K. (2016). Understanding the role of technology in adolescent dating and dating violence. Journal of Child and Family Studies, 25(1), 308-320. https://doi. org/10.1007/s10826-015-0196-5

Bates, S. (2016). Revenge porn and mental health: A qualitative analysis of the mental health effects of revenge porn on female survivors. Feminist Criminology, 12(1), 22-42. https:// doi.org/10.1177/1557085116654565

Belknap, J., Chu, A. T., \& DePrince, A. P. (2012). The roles of phones and computers in threatening and abusing women victims of male intimate partner violence. Duke Journal of Gender Law and Policy, 19, 373-406.

Beydoun, H. A., Williams, M., Beydoun, M. A., Eid, S. M., \& Zonderman, A. B. (2017). Relationship of physical intimate partner violence with mental health diagnoses in the nationwide emergency department sample. Journal of Women's Health, 26(2), 141-151. http://doi.org/10.1089/jwh.2016.5840

Blay, E. A. (2014). Feminismos e masculinidades: os impasses da violência contra a mulher. In E. A. Blay. (Org.) Feminismos e masculinidades: novos caminhos para enfrentar a violência contra a mulher. (pp. 11-28). Cultura Acadêmica.

Borrajo, E., Gámez Guadix, M., \& Calvete, E. (2015). Justification beliefs of violence, myths about love and cyber dating abuse. Psicothema, 27(4), 327-333. http://doi.org/10.7334/ psicothema2015.59

Brasil (2006) Lei $n^{\circ} 11340$ de 07 de agosto de 2006. Cria mecanismos para coibir a violência doméstica e familiar contra a mulher, nos termos do $\S 80$ do art. 226 da Constituição Federal, da Convenção sobre a Eliminação de Todas as Formas de Discriminação contra as Mulheres e da Convenção Interamericana para Prevenir, Punir e Erradicar a Violência contra a Mulher; dispõe sobre a criação dos Juizados de Violência Doméstica e Familiar contra a Mulher; altera o Código de Processo Penal, o Código Penal e a Lei de Execução Penal; e dá outras providências. http://www.planalto.gov.br/ ccivil_03/_ato2004-2006/2006/lei/l11340.htm 


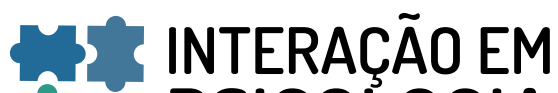 ETS PSICOLOGIA}

Brasil (2012) Lei n 12737 de 30 de novembro de 2012. Dispõe sobre a tipificação criminal de delitos informáticos; altera o Decreto-Lei no 2.848, de 7 de dezembro de 1940 - Código Penal; e dá outras providências. http://www.planalto.gov.br/ ccivil_03/_ato2011-2014/2012/lei/l12737.htm

Brasil (2018) Lei no 13642 de 03 de abril de 2018. Altera a Lei $n^{\circ} 10.446$, de 8 de maio de 2002, para acrescentar atribuição à Polícia Federal no que concerne à investigação de crimes praticados por meio da rede mundial de computadores que difundam conteúdo misógino, definidos como aqueles que propagam o ódio ou a aversão às mulheres. http://www.planalto.gov.br/ccivil_03/_Ato2015-2018/2018/Lei/L13642. htm

Braun, V., \& Clarke, V. (2006). Using thematic analysis in psychology. Qualitative research in psychology, 3(2), 77-101. https://doi.org/10.1191/1478088706qp063oa

Burris, A. (2014). Hell hath no fury like a woman porned: Revenge porn and the need for a federal nonconsensual pornography statute. Florida Law Review, 66, 2325-2359.

Cardoso, B. L. A., \& Costa, N. (2019). Habilidades Sociais e Violência Contra a Mulher por Parceiro Íntimo. Interação em Psicologia, 23(1), 20-32. http://doi.org/10.5380/psi. v23i1.53789

Carline, A., Gunby, C. \& Taylor, S. (2018). Too drunk to consent? Exploring the contestations and disruptions in male-focused sexual violence prevention interventions. Social \& Legal Studies, 27(3), 299-322. http://doi. org/10.1177/0964663917713346

Cerqueira, D. (2014). Demografia e homicídios no Brasil. In A. A. Camarano (Org.). Novo regime demográfico: uma nova relação entre população e desenvolvimento? (pp. 355-373). IPEA.

Cerqueira, D.,Bueno, S., Alves, P. P., Lima, R. S., Silva, E. R. A., Ferreira, H., Pimentel, A., Barros, B., Marques, D., Pacheco, D., Lins, G. O. A., Lino, I. R., Sobral, I., Figueiredo, I., Martins, J., Armstrong, K. C., \& Figueiredo, T. S. (2020). Atlas da violência 2020. IPEA. https://www.ipea.gov.br/atlasviolencia/ download/24/atlas-da-violencia-2020

Citron, D. K., \& Franks, M. A. (2014). Criminalizing revenge porn. Wake Forest Law Review, 49, 345-391.

Colossi, P. M., Marasca, A. R., \& Falcke, D. (2015). De geração em geração: a violência conjugal e as experiências na família de origem. Psico, 46(4), 493-502. https://doi. org/10.15448/1980-8623.2015.4.20979

Cortez, M. B. (2006). Gender conceptions: an angle to study violence against women. In A. Garcia (Org.) Relacionamento interpessoal: estudos e pesquisas. (pp.136-138). UFES.

Cortez, M. B. (2012). "Sem açúcar, com afeto": estudo crítico de denúncias de violência contra as mulheres e dos paradoxos da judicialização. ( [Tese de doutorado, Universidade Federal do Espírito Santo]. Repositório Institucional da Universidade Federal do Espírito Santo. http://repositorio.ufes.br/ handle/10/3137
Cunha, V. B., \& Nascimento, P. D. do (2015). Pensando a educação popular e participação social para mulheres em situação de violência doméstica em Teresina. Revista Eletrônica Gestão e Saúde, 6(1), 734-750. https://periodicos.unb.br/ index.php/rgs/article/view/2705

Drouin, M., Coupe, M., \& Temple, J. R. (2017). Is sexting good for your relationship? It depends.... Computers in Human Behavior, 75, 749-756. https://doi.org/10.1016/j. chb.2017.06.018

Dutra, M. D. L., Prates, P. L., Nakamura, E., \& Villela, W. V. (2013). A configuração da rede social de mulheres em situação de violência doméstica. Ciência \& Saúde Coletiva, 18(5), 1293-1304. https://doi.org/10.1590/S141381232013000500014

Estébanez, L., \& Vazquez, N. (2013). Las redes sociales: Una nueva forma de expresarse, comunicarse y relacionarse. In: L. Estébanez \& N. Vazquez. La desigualdad de género y el sexismo en las redes sociales (pp. 11-19). (Coleccíon Gazteak, v. 7). Servicio Central de Publicaciones del Gobierno Vasco.

Flach, R. M. D., \& Deslandes, S. F. (2017). Abuso digital nos relacionamentos afetivo-sexuais: uma análise bibliográfica. Cadernos de Saúde Pública, 33(7), 1-19. https://doi.or$\mathrm{g} / 10.15090 / 0102-311 \times 00138516$

Flick, U. (2008). Introdução à pesquisa qualitativa. Artmed. (Obra original publicada em 1998).

Guimarães, F. L., \& Diniz, G. R. S. (2017). Masculinidades, duplo-vínculo e violência conjugal contra a mulher. In: C. Stevens, S. Oliveira, V. Zanello, E. Silva, \& C. Portela (Orgs.). Mulheres e violências: interseccionalidades. (pp. 586-605). Tecnopolitik. https://repositorio.unb.br/handle/10482/35386

Haack, K. R., \& Falcke, D. (2013). Infidelid@ de. com: Infidelidade em relacionamentos amorosos mediados e não mediados pela Internet. Psicologia em Revista, 19(2), 305-327. https://doi.org/10.5752/P.1678-9563.2013v19n2p305

Instagram. (2020). Sobre nós. https://about.instagram.com/ about-us

Marganski, A. (2013). Virtual Relationship Violence and Perspectives on Punishment: Do Gender or Nationality Matter? Future Internet, 5(3), 301-316. https://doi.org/10.3390/ fi5030301

Marganski, A., \& Melander, L. (2015). Intimate partner violence victimization in the cyber and real world: Examining the extent of cyber aggression experiences and its association with in-person dating violence. Journal of interpersonal violence, 33(7), 1071-1095. https://doi. org/10.1177/0886260515614283

Martinéz-Pecino, R., \& Durán, M. (2016). I love you but I cyberbully you: the role of hostile sexism. Journal of interpersonal violence, 34(4), 1-16. https://doi. org/10.1177/0886260516645817 


\section{H MTERAC̄OAEM ET PSICOLOGIA}

Medeiros, M. N. \& Tavares, M (2017). Construção e validação de checklist de avaliação de risco de violência contra muIher nas relações de intimidade. In: C. Stevens, S. Oliveira, V. Zanello, E. Silva, \& C. Portela (Orgs.). Mulheres e violências: interseccionalidades. (pp. 546-568). Tecnopolitik. https://repositorio.unb.br/handle/10482/35386

Messinger, A. M., Birmingham, R. S. \& DeKeseredy, W. S. (2018). Perceptions of same-gender and different-gender intimate partner cyber-monitoring. Journal of interpersonal

violence, 1, 21. https://doi.org/10.1177/0886260518787814

Nascimento, O. C., Costa, M. C. O., Costa, A. M. \& Cunha, B. D. S. G. (2018). Violência no percurso amoroso e saúde mental de adolescentes-jovens: revisão integrativa. Revista de Saúde Coletiva da UEFS, 8(1), 30-38. https://doi.org/10.13102/ rscdauefs.v8.3505 https://doi.org/10.13102/rscdauefs. v8i1.3505

Nova, F. F., Rifat, M. D., Saha, P., Ahmed, S. I. \& Guha, S. (2019. Janeiro). Online Sexual Harassment over Anonymous Social Media in Bangladesh [Apresentação de artigo] Proceedings of the Tenth International Conference on Information and Communication Technologies and Development (ICTD '19). Ahmedabad, India. https://dl.acm.org/ doi/10.1145/3287098.3287107

Organização Mundial da Saúde. (2012). Understanding and addressing violence against women: intimate partner violence. https://apps.who.int/iris/handle/10665/77432

Organização Mundial da Saúde. (2013). Global and regional estimates of violence against women: prevalence and health effects of intimate partner violence and non-partner sexual violence. https://www.who.int/reproductivehealth/publications/violence/9789241564625/en/

Organização Mundial da Saúde. (2017). Violence against women. https://www.who.int/en/news-room/fact-sheets/detail/violence-against-women

Organização Mundial da Saúde. (2019). Respect women: preventing violence against women. https://www.who.int/reproductivehealth/publications/preventing-vaw-framework-policymakers/en/

Organização Mundial da Saúde. (2020). COVID-19 and violence against women: what the health sector/system can do. World Health Organization. https://www.who.int/reproductivehealth/publications/vaw-covid-19/en

Parker, I. (2015). A link in the chain: The role of friends and family in tackling domestic abuse. Citizens Advice. https://www.citizensadvice.org.uk/Global/CitizensAdvice/ Crime\%20and\%20Justice\%20Publications/Linkinthechain-ExecSum.pdf

Patchin, J. W., \& Hinduja, S. (2006). Bullies move beyond the schoolyard: A preliminary look at cyberbullying. Youth violence and juvenile justice, 4(2), 148-169. https://doi. org/10.1177/1541204006286288
Pedrosa, C. M. \& Spink, M. J. P. (2011). A violência contra muIher no cotidiano dos serviços de saúde: desafios para a formação médica. Saúde e Sociedade, 20(1), 124-135. https://doi.org/10.1590/S0104-12902011000100015

Pereira, D. D. D. S. (2018). Funcionamento discursivo das hashtags: um olhar para a \#somostodos. ([Dissertação de mestrado, Universidade Estadual de Campinas]. Repositório da Produção Científica e Intelectual da Unicamp. http://repositorio.unicamp.br/jspui/handle/REPOSIP/332362

Scarpati, A. S. (2013). Os mitos de estupro e a (Im)parcialidade jurídica: a percepção de estudantes de direito sobre mulheres vítimas de violência sexual. ([Dissertação de mestrado, Universidade Federal do Espírito Santo]. Repositório Institucional da Universidade Federal do Espírito Santo. http:// repositorio.ufes.br/handle/10/3071

Schoenmaker, M., Gessner, R., Fornari, L., Fonseca, R. \& Oliveira, R. (2016). A violência por parceiro íntimo entre adolescentes: percepções a partir de um jogo online. Atas-Investigação Qualitativa em Saúde, 2, 12-14. https://proceedings. ciaiq.org/index.php/ciaiq2016/article/view/819

Schraiber, L. B., d'Oliveira, A. F. P., França-Junior, I., Diniz, S., Portella, A. P., Ludermir, A. B., Valência, O., \& Couto, M. T. (2007). Prevalência da violência contra a mulher por parceiro íntimo em regiões do Brasil. Revista de Saúde Pública, 41(5), 797807. https://doi.org/10.1590/S0034-89102007000500014

Recuero, R. (2012). Comunicação mediada pelo computador e conversação. In: R. Recuero (Org.) Comunicação, Cultura de Rede e Jornalismo (pp. 21-60). Sulina.

Rocha, M. C. J. (2015). Socializações generizadas e novas formas de violência sobre as mulheres: o caso do Facebook. In: T. S. A. M. Brabo (Org.) Mulheres, Gênero e Violência (pp. 201-223). Cultura Acadêmica.

UN Women. (2015). Cyber Violence Against Women and Girls: A World-Wide Wake-Up Call. United Nations: Broadband Commission for Digital Development Working Group on Broadband and Gender. https://www.broadbandcommission. org/publication/cyber-violence-against-women/

Vinuto, J. (2014). A amostragem bola de neve na pesquisa qualitativa: um debate em aberto. Temáticas, 22(44), 203-220. https://doi.org/10.20396/tematicas.v22i44.10977.

Waiselfisz, J. J. (2015). Mapa da violência 2015: Homicídio de Mulheres no Brasil. ONU Mulheres; OPAS/OMS; Secretaria Especial de Políticas para as Mulheres; \& Flacso. https:// www.mapadaviolencia.net.br/mapa2015_mulheres.php

Walker, L. E. (1979). The battered woman. Sage.

Data de submissão: 02/03/2020 Primeira decisão editorial: 07/09/2020 Aceite em 14/10/2020 